\title{
NOTAS
}

\section{El Personaje y su Doble en las Ficciones de Cortázar}

\begin{abstract}
A NTEs de publicar Rayuela (1963) Julio Cortázar era conocido prinA cipalmente como cuentista, ya que su primera novela, Los Premios (I9ro), fue considerada un genial pero malogrado ensayo. Rayuela lo cónvierte en figura literaria mundial y suscita una serie de comentarios y controversias con su audacia, con sus deliberadas dificultades, y enj especial, con las teorías novelísticas que ilustra y discute. Es en estar obra donde Cortázar utiliza en forma más obvia y dominante el tema del doble, del doppelgänger literario, personificado por Oliveira y Traveler, La Maga y Talita. Interesa anotar que este recurso, de antigua tradición literaria, aparece desde sus primeros cuentos de Bestiario (195I), y reaparece como una fidelidad sorprendente en las colecciones de relatos que le siguen: Final de juego (1956), Las armas secretas (1959) y con posterioridad a Rayuela, en Todos los fuegos el fuego (I966).

En general, podría decirse que Cortázar no utiliza el doble en el sentido usual de duplicación de la personalidad, ni de confusión entra lo que podría llamarse el personaje real o su imagen. Tanto el original como el reflejo tienen similar importancia, no hay subordinación de una al otro, y no importa a menudo clarificar, porque a menudo no exista diferencia definitiva, cuál es el personaje principal y cual el advenedizo.2

I Usamos el vocablo en el sentido en que E. T. A. Hoffmann lo usó, y de acuerdo en la definición de Jean Paul Richter: "So heissen Leute die sich selbst sehen" (Siebenkäs) Werke, Hist.-krit. (Weimar, 1927) Abt I, vol. VI, p. 54.

Véase también el artículo sobre "Doppelgänger" en Trübners Deutsches Wörterbuch, ed. A. Götze (Berlin, 1939) y la abundante bibliografía sobre el tema en la literatura romántica alemana, en especial sobre E.T.A. Hoffmann.

2 Con el título de "Doubles" hay un excelente artículo sobre el origen y
\end{abstract}


En casi todos los casos, la imagen doble permite posibilidades de enriquecimiento vital, asomarse a zonas ignoradas o remotas como si las viviéramos, no como mera visita extraña y ajena a esa atmósfera. Un ejemplo de esto y un caso común en las ficciones de Cortázar es la aparición del actor-lector, el personaje que está dentro y fuera de la ficción, tal comor aparece en sus relatos Continuidad de los parques y Lejana. No se trata de una rebelión pirandelliana o unamunesca del personaje: al contrario es una verdadera función doble, en la que el personaje se ve como tak desde fuera de la narrativa, como un director que conoce el guión escénico y sabe muy bien lo que ocurrirá después, no como ser enajenado. Conviene destacar ya que no se trata de una pérdida de conciencia: el personaje, una vez ausentado de la narración, no deja de pensar al mismor tiempo como personaje y como director. Tal es el caso del personaje de Continuidad de los parques, ${ }^{3}$ que se sienta a leer una novela en la que aparece un triángulo amoroso y es testigo de la reunión de una esposa, infiel y su amante. Luego de presenciar los preparativos de asesinato quel hace el último, lo ve avanzar a espaldas de un sillón en el que yace sentada su víctima: el lector-espectador-marido. El personaje está dentro y fuera de la novela que lee en la continuidad de un parque de naturaleza ya metafísica que lo lleva de personaje a testigo en una presentación de vida y destino que no cesa ni tiene divisorias: va de la realidad a la ficción y pareciera que ésta triunfase en la imagen del asesino que avanza sigilosamente, al final del relato, hacia el lector-víctima.

En Lejana se revelan las visiones que tiene una muier que vive aparentemente en Buenos Aires, y que a menudo sueña, despierta, con una doble que vive en Hungría. Se trata no sólo de ensoñaciones diurnas, sino que son anotadas posteriormente en un diario, y no se pueden considerar alucinaciones, pues son verdaderos momentos de comunicación, durante los cuales el personaje llega a sentir la nieve en los zapatos que hace tiritar a su doble en Hungría. Siente físicamente el frío y los cardenales de remotos castigos que sufre la otra. El ambiente en que existe el personaje principal, Alina Reyes, tiene un aire tan afantasmado como el de la doble de Hungría;" quizás más aún, porque está

naturaleza del doble, por división o multiplicación, en la Encyclopedia of Religion and Ethics, Ed. Hastings, Scribner's (New York, 1951), vol. V.

3 En el Boletin de literaturas bispánicas de la Facultad de Filosofía $y$ Letras de la Universidad del Litoral, N 6. Argentina, Rosa Boldori, en su artículo "La irrealidad en la narrativa de Cortázar", habla de "confusión del plano literario con el real" al comentar este cuento. Nos parece que los planos no se confunden en el sentido lato, sino que el personaje vive en ambos, guardando conciencia pero manteniendo separadas las dos vivencias correspondientes.

"Alina comenta sobre sus visiones mientras asiste a un concierto: "... vengan 
totalmente traspasado por las comunicaciones - por así decirlo- con la doble, que se insinúan entre fragmentos de la vida del personaje.

Alina Reyes es una especie de anagrama vivo: dentro de su yo pueden darse otras combinaciones, como la otra de Hungría. Su nombre: Alina Reyes, puede ser, en la otra: "y es la reina"; sugiriendo vagamente la idea, finalmente negada, de la soberana y la impostora. Pero el final del relato trae una unión verdadera y física, cosa no muy corriente en Cortázar, y en un abrazo que se dan la viajera de Argentina y la húngara, se unen en un puente a menudo soñado, en Budapest. Pero la unión es breve; después de la breve fusión, la otra se vuelve la una, se traspasa al cuerpo de Alina en su elegante traje gris, y Alina se queda en la doble, tiritando mientras siente el frío, ya familiar, de la nieve que le entra en los zapatos.

Vemos cómo el personaje siente al otro simultáneamente y sigue siendo él mismo, como si además de su función normal, conocida, participara de otro destino, a ratos, y fragmentariamente. No se trata entonces del problema de la división de la personalidad, y la consiguiente esquizofrenia, sino de un verdadero enriquecimiento de posibilidades vitales, luego negadas al participar de dos destinos, o de un orden personal y otro ampliado, que incluye a otros seres vagamente conocidos, y pertenecientes a un orden que comparten con el personaje. Esta participación en más de un destino, se asemeja a un juego en el que el movimiento de una pieza puede afectar la posición o la suerte de otra. De alli la preferencia de Cortázar por ciertos tipos de juegos en los cuales las combinaciones o jugadas pueden ser múltiples y diversas, dentro de un orden o reglas fijas, como el ajedrez, las damas, el billar, la misma rayuela y los anagramas. Vale decir, dentro de una figura, muchos posibles aspectos. James Irby ha anotado con acierto la presencia de estas "figuras" en la obra de Cortázar.5 Dichas figuras, como los dobles, consisten en posibles aspectos o ampliaciones del yo. 6

Una variante de este juego aparece en los cuentos que tratan de un avatar no consecutivo, sino semi-simultáneo, que permite a un personaje del relato "La flor amarilla" encontrar a un niño en el autobús, que es su futura imagen. Esto le da conciencia de su inmortalidad y se

a decirme de otra que le haya pasado lo mismo, que viaje a Hungria en pleno Odeón. Eso le da frío a cualquiera che, aquí o en Francia". (Bestiario, Buenos Aires. 1951). p. 35.

5 James E. Irby: "Cortázar, Hopscotch and Other Games", Novel, Vol. I, $N^{\circ}$ I, Fall 1967, pp. 64-70.

6 Ver las declaraciones del propio Cortázar en el libro de Luis Harss Into de Mainstream (New York 1967 ). 
asocia obsesivamente con el chico y su familia. Pero la muerte imprevista y no muy sentida del joven, lo devuelve a la noción de la nada y vuelve a frecuentar los autobuses en busca de un nuevo avatar. La originalidad del relato consiste en que con la conciencia de la mortalidad se produce un estado de paz, al que sobreviene una ansiedad febril al descubrir nuevamente que debe existir en alguna parte, otro avatar que lo devuelva al mundo de los inmortales, aunque más no sea para poder perpetuar el goce por la belleza por esa "flor amarilla" que inesperadamente restaura sentido a la inacabable cadena.

En Las armas secretas nos encontramos con otro tipo de avatar: un joven francés que repite, sin saberlo, pero recordando vagamente, algo ya hecho: los actos de un soldado alemán que violó siete años atrás, a la que es ahora su novia. El joven no conoce este episodio, su novia nó lo: ha mencionado jamás, pero desde el principio de sus relaciones comienza a recordar y a asociar la letra en alemán de una canción de Schumann, cada vez que piensa en la muchacha. Aunque su realidad es otra, lo imaginado por él coincide con lo. vivido por el alemán, como si se tratara de una porosidad de conciencias, y eso explica su convencimiento de que ella, la novia, lo va a delatar, como hiciera de chiquilla, siete años atrás, con el violador. El muchacho está dentro de su personaje y, vagamente y a ratos, en el otro. Es los dos; seductor ahora y violador que fue. Tampoco se trata de actos opuestos, sino de que la seducción y la violación parecen confundirse en un único acto amatorio, con una diferencia mínima de detalles. El muchacho no se siente enajenado, compara su memoria o sus imágenes mentales -recuerdos de otra concienciay comprueba que la realidad desdice, en muchos casos, sus vagas intuiciones. Se trata de una repetición de actos no exactamente iguales, tan sólo similares; está hundido en dos realidades al mismo tiempo: es $\mathrm{Mi}$ chel y 'el alemán. En el cuento es también los dos para la novia, en quien reaviva recuerdos muy penosos, así como para los amigos de ella, que ven en él al que puede corregir o enmendar, con su amor, el acto de siete años atrás. En rigor, él es, en este doble esquema simultáneo, un personaje doble, que juega su papel a plena conciencia, y el del otro, con creciente intuición del mismo.

El joven francés, al encontrarse en circunstancias similares - aunque no idénticas - comienza a repetir los actos del otro, a cavilar sobre pensamientos que le son ajenos, pero no extraños. Esta gradual identificación interior es quizá el rasgo más notable del personaje, que en el acto final de la seducción ha dejado de ser él mismo, y se admira de la falta de resistencia por parte de su novia. 
En el cuento $E l$ río también aparece una imagen doble en la esposa que ha amenazado ahogarse en el Sena. Las imágenes las ve el marido, entre dormido y despierto, con la vaga memoria de que ella acaba de marcharse para arrojarse al río. El recuerda la visión anterior de la ahogada, siempre hipotética, ficción urdida por ella en sus frecuentes amenazas: así la ve aún en la cama como en el fondo de un sueño:

...p porque te habías ido diciendo alguna cosa, que te ibas a ahogar en el Sena, o sea que has tenido miedo, has renunciado y de golpe estás abí casi tocándome, y te mueves ondulando ...7

El sueño nos deja con la duda de si la figura de la mujer ahogada en el río es realidad o ficción, pero lo mismo ocurre con la imagen de la mujer en el lecho, quien, descrita y recargada de nimios déalles familiares, repetida y revista por el marido durante años, se nos impone con su realidad. Pero gradualmente las expresiones del narrador-marido establecen que la imagen final de la mujer ahogada en el río es la real:

... voy doblando los juncos de tus brazos, me ciño a tu placer de manos crispadas, de ojos enormemente abiertos, ahora tu ritmo al fin se ahonda en movimientos lentos de muaré, de profundas burbujas ascendiendo hasta $\mathrm{mi}$ cara, vagamente acaricio tu pelo derramado en la almohada, en la penumbra verde mito con sorpresa mi mano que chorrea, y antes de resbalar a tu lado sé que acaban de sacarte del agua, demasiado tarde, naturalmente $\ldots{ }^{8}$

En este final, la figura de la mujer dormida y de la ahogada se confunden en una misma situación, en una cama-río, desde la que desafían la lucidez del marido-narrador.

En La noche boca arriba sucede algo similar. La víctima de un accidente de motocicleta espera la acción del cirujano que se le acerca con un objeto en la mano. En las sucesivas noches de fiebre se intercalan sueños episódicos y progresivos de un tolteca que es atrapado y condenado al sacrificio durante la guerra florida. Este sueño es interrumpido por momentos de plácida vigilia en el hospital, pero gradualmente al enfermo le cuesta más y más ahuyentar la pesadilla que lo posee, y se nos revela que ésta es la realidad, mientras que la situación del accidentado en el hospital, con la rutina de febrífugos, calmantes y visitas

7 Final de juego (Buenos Aires, 1964), p. 19 [el subrayado es nuestro].

B Loc. cit., p. 22. (El subrayado es nuestro). 
médicas, es sólo un sueño, boca arriba, de esa víctima que en efecto marcha al sacrificio, no de la sala de operaciones, sino del "teocalli" donde le espera, en vez del cirujano con el bisturí. el sacerdote con el cuchillo de obsidiana. ${ }^{9}$ La dificultad en determinar sueño y realidad queda acentuada mediante el natural impulso por identificar la pesadilla con lo horrible, lo pasado y conocido; pero aquí se trata de un sueño realista y de una realidad horripilante, pesadillesca.

La imagen de un ser desaparecido ya, que retorna para cumplit su destino verdadero de un ser culaquiera que se le parece vagamente, aparece en Cartas de mamá y Las puertas del cielo. En el primer cuento la pareja ha hurtado su felicidad al cuñado, posteriormente muerto de tisis. Sintiéndose culpables, marido y mujer mantienen y crean la idea de que Nico, el cuñado, vive aún, y en realidad él sobrevive en los silencios que omiten su nombre, en la lejanía geográfica de los lugares familiares que la pareja se ha impuesto, y en las pesadillas de ella, la ex novia del desaparecido.

Por un desliz, real o verdadero, en una carta de la madre lejana, Nico entra abiertamente otra vez en sus vidas: se anuncia su partida de Buenos Aires a París. La madre no revela ningún otro indicio de enajenación mental, y la realidad del anuncio se implanta en la conciencia de la pareja. La mujer, su ex-novia, lo va a esperar a St. Lazare; el marido la sigue y ambos ven, por separado, una figura semejante a Nico que baja del tren, una especia de doble a quien dejan pasar sin hablarle. Luego, de nuevo en la soledad de su casa, marido y mujer admiten haberlo reconocido con un trivial:

-A vos ¿no te parece que está mucho más flaco?

-Un poco... uno va cambiando ... ${ }^{10}$

que desdice la irrealidad del encuentro. Pero esto no es tal. Si pensamos en la extraordinaria vitalidad que la memoria de Nico ha tenido en estas dos vidas, acrecentada por los silencios, la deliberada omisión de los recuerdos comunes y los desengaños del matrimonio. El Nico reconocido en un viajero que se le parece, está cumpliendo su destino verdadero de intruso, de víctima convertida en victimario, según reina en la conciencia de los esposos. Esta imagen es mucho más real que la del novio

9 James E. Irby, loc. cit., difiere en su interpretación de este cuento: "... a young man injured in a traffic accident repeatedly slips, as he lies in the hospital, into the nightmare of being a sacrificial victim in ancient Mexico, which finally engults bim as the only reality". [El subrayado es nuestro].

10 Lats armas secretas (Buenos Aires, 1959); p. 36. 
rechazado y resignado que se murió de tisis sin hacer un reproche. El doble es ese Nico que ellos comenzaron a fraguar en Buenos Aires y acabaron de dar forma en sus silencios de París.

Caso semejante se presenta en Las puertas del cielo, en el personaje de Celina, la ex-bailarina de milonga, canalla que después de haberse escapado a la vida decente en un matrimonio no exento de ternura, y una vez muerta, reaparece, como Nico en el cuento anterior, para cumplir su verdadero destino. La reconocen el viudo y un amigo una noche que van a la milonga y ven brevemente a una bailarina que se le parece. Celina, reencarnada, es la que debió ser, si pudiera haber cumplido su destino de milonguera, sin canalla, gozando este paraiso de arrabal que le brindaba el tango.

Para finalizar, mencionaremos otros dos cuentos: Las cícladas y Axolon, en los cuales se produce la identificación con algo no humano, con la cultura - a través de un ídolo-y con un ser entre pez y batracio. El narrador descubre en ambos casos una extraordinaria afinidad espiritual con un ser con el que no tiene ni la más remota similitud física ni circunstancial. Al contrario, cuanto más distante en apariencia tanto más angustiosa la similitud de la condición espiritual. En los dos relatos se trata de una identificación con otra existencia como acto de voluntad. Los personajes siguen, como en los casos ya vistos, siendo ellos y lo otro hasta que se produce un traspaso final de existencia, sin que se pierdan totalmente algunos elementos de una conciencia, al fundirse con otra. En Las cicladas se trata de los esfuerzos de un arqueólogo neurótico que quiere establecer contacto efectivo con el ídolo que ha excavado, $y$ en el otro cuento, de establecer contacto con los axolotl - peces batracios - en lo que se podría llamar una verdadera licantropía espiritual. Estos seres casi anfibios revelan, en la impasibilidad de unos ojos dorados, irrevertiblemente no-humanos, la posibilidad de un mundo espiritual vasto y desconocido. Instistamos en el hecho de que contacto no implica comunicación, y el narrador-personaje deliberadamente omite las explicaciones racionales o pseudo científicas. Acepta el hecho consumado de una afinidad espiritual, de un estado de "simpatía" que facilita una comunicación supra-lógica. ${ }^{11}$ En ambos casos no se verifica una pérdida de conciencia, pues esto implicaría una mera transferencia. Los personajes viven o ven y aceptan la dualidad como una forma de posible enri-

11 En este sentido Cortázar se acerca mucho a las teorías anímicas de los Mesmeristas, que influyeron tanto en los románticos alemanes, pero parece totalmente alejado de los conceptos "mágicos" atribuidos a las sombras - y los doblesen las culturas primitivas, según las analizan Frazer (The Golden Bough) y L. Lévy-Bruhl ( $T$ be Soul of the Primitive). 
quecimiento vital, no siempre logrado, o de rectificación de un destino desviado, o falso.

En los cuentos mencionados, el yo de los personajes se difunde, o trata de hacerlo, en otros destinos, a veces elegidos, presentidos o vagamente intuidos como parte de un legado atávico. El resultado inmediato es que el yo se observa a sí mismo, se ve como actor y espectador, se sitúa, en suma, fuera de la materia literaria en la enajenación más total; no obstante, retiene su facultad observante y narrativa, de una realidad a la que indefectiblemente ya no pertenece, pero que quiere conocer, pues lo que jamás pierde es el impulso de establecer contacto con esos otros posibles yo, de tocar fondo en esas realidades tan similares y sin embargo remotas.

En todos los casos la presencia del doble implica una ampliación de la experiencia, no una deformación de la misma, pero esta ampliación no es por agregado de si uaciones totalmente nuevas, sino vagamente intuidas o recordadas como cosa recobrada, como intento de establecer puentes $^{12}$ - tan frecuentes en la obra de Cortázar - no con todas las cria. turas, sino con algunas en cuyas vidas participamos como estrellas que forman parte de una constelación.

El tema del doble, en estos relatos, no sirve para presentar la conocida escición de la personalidad, ni el problema de discernir la imagen verdadera entre las adventicias; se trata de vidas en dos planos, el personal, restringido, y uno más amplio, mágico, ${ }^{13}$ pero aceptado como cosa natural, a menudo buscado en acto de voluntad en un esfuerzo por reintegrarse a un orden misterioso y trascendente del cual forman parte estos juegos de destinos múltiples que sólo en ciertos momentos se nos revelan.

\section{Marta Morello-Frosch}

\section{The Obio State University}

12 Véase el interesante artículo bajo el título de "Bridge" sobre el valor mítico de los puentes que aparece en E. and M. A. Radford Encyclopedia of superstitions (London, 1961).

Recuérdese el comentado pasaje de Royueld en el que Talita trata de establecer un puente sobre un precario tablón, entre Traveler y Oliveira. laciones".

13 Cortázar en sus declaraciones a Luis Harss, loc. cit., habla de "conste- 